\title{
Correction to: Identification of fracture models based on phase field for crack propagation in heterogeneous lattices in a context of non-separated scales
}

\author{
Nhu Nguyen ${ }^{1} \cdot$ J. Yvonnet ${ }^{1} \cdot$ J. Réthoré ${ }^{2}$ A. B. $\operatorname{Tran}^{3}$
}

Published online: 26 November 2018

(c) Springer-Verlag GmbH Germany, part of Springer Nature 2018

\section{Correction to: \\ Computational Mechanics https://doi.org/10.1007/s00466-018-1636-z}

The original article was published with an error in the acknowledgement section. The complete acknowledgement section is given below.

Acknowledgements This research is funded by Vietnam National Foundation for Science and Technology Development (NAFOSTED) under Grant Number 107.02-2017.309. The financial support of Institut Universitaire de France (IUF) for J.Y. is gratefully acknowledged.

Publisher's Note Springer Nature remains neutral with regard to jurisdictional claims in published maps and institutional affiliations.

The original article can be found online at https://doi.org/10.1007/ s00466-018-1636-z.

J. Yvonnet

julien.yvonnet@univ-paris-est.fr

1 Laboratoire Modélisation et Simulation Multi Échelle, MSME UMR 8208 CNRS, Université Paris-Est, 5 bd Descartes, 77454 Marne-la-Vallée, France

2 Institut de Recherche en Génie Civil et Mécanique-GeM, UMR CNRS 6183, École Centrale de Nantes, 1 rue de la Noë, 44321 Nantes, France

3 National University of Civil Engineering, 55 Giai Phong street, Ha Noi, Vietnam 